\title{
La recuperación de los comunes en el sur-austral: construcción institucional de Espacios Costeros Marinos de Pueblos Originarios
}

\author{
Forencia Diestre de la Barra \\ Universidad de Chile, Santiago, Chile \\ Email: f.diestre@gmail.com \\ Franc isco Araos Leiva \\ Universidad de Los Lagos, Osomo, Chile \\ Email: francisco.araos@ulagos.cl
}

Recibido: $\mathbf{1 4 . 0 6 . 2 0 ~ | ~ A c e p t a d o : ~} \mathbf{1 3 . 0 8 . 2 0}$

\begin{abstract}
Resumen: La creación de los Espa cios Costeros Marinos para Pueblos Origina rios (ECMPOs) pone de ma nifiesto las disputa s por los recursos comunes a ra iga das en intera c ciones entre usuarios que mantienen intereses divergentes sobre la zona marino-costera. Aplicando la propuesta a nalítica de la Ecología política neo-instituciona lista y el a ná lisis de encua dre o frame, el artíc ulo a naliza el proceso de construcción institucional para la recuperación de los comunes mediante la creación e implementación de ECMPOs en el sur-austral de Chile. En este proceso las posiciones de los grupos de interés son legitimadasa tra vés de disc ursos y narrativas donde se contrapone la visión de los espacios costeros como limitantes del desarrollo local y regional, y aquella visión que los respalda como herramienta clave para el resguardo de los comunes y del temitorio.
\end{abstract}

Palabras clave: Espacios Costeros para Pueblos Originarios; construc ción institucional; recursos comunes; pueblos oniginarios; Chile.

\section{The recovery of the commons in southem Chile: institutional construc tion of the Indigenous Marine Areas}

\begin{abstract}
The establishment of the Indigenous Marine Areas (IMAs or ECMPOS in Spanish) highlights the disputes over the common pool resources, which are rooted in interactions between users who have divergent stakes over the marine and coastal zone. Based on the analytical proposal of the New Institutional Political Ecology and the frame analysis, the a ric le explores the institutional c onstruction process related to the rec overy of the commons through the creation and implementation of IMAs in southem Chile. In this process, the positions of the stakeholders are legitimized through discourses and narratives where the vision of the IMAs as a limit of the local and regional development is contrasted with the vision that supports them as a key tool for the protection of the commons and the teritory. Keywords: Indigenous Marine Areas; institutional building; common resources; indigenous people; Chile.
\end{abstract}




\section{A rec uperação dos bens comuns no sul austral do Chile: construção institucional dos Espaços Costeiros Marinhos para os Povos Indígenas}

Resumo: A cria ção dos Espaç os Costeiros Ma rinhospa ra Povos Indíg enas (ECMPOs) visibiliza as disputas pelos rec urso s comuns, ba sea das nas intera ções entre usuá rios com interesses divergentes sobre a zona marinha e costeira. Com base no marco teórico da Ecologia polític a neo-institucionalista (Haller, 2019) e dos frames, o artigo a nalisa o processo de construção institucional para a recuperação dos bens comuns, através da criação e implementação de ECMPOsno sul a ustral do Chile. Neste processo, as posições dos grupos de interesses são legitima das a través de discursos e na rrativas onde a visão dos espaços costeiros como limitantes do desenvolvimento local e regional se opõe àquela visão que os coloca como uma ferramenta chave para a proteção dos bens comuns e do teritório. Palabras-chave: Espa ços Costeiros Ma rinhospara Povos Ind ígenas; c onstrução institucional; recursos comuns; povos indígenas; Chile.

\section{Como citar este artículo:}

Diestre de la Barra, F. y Ara os Leiva, F. (2020). La recuperación de los comunes en el sura ustral: construcción institucional de Espa cios Costeros Marinos de Pueblos O riginarios. Polis Revista La tinoa meric ana, (57), 13-36. doi: http:// dx.doi.org/10.32735/S0718-6568/2021N57-1562

\section{Introducción}

La disputa por los bienes comunes del mar de Chile tiene una larga historia. Desde el conflic to por el acceso a la zona litoral y la explotación de recursos por parte de pescadores «despla ya dos» en el litoral c entral a comienzos del siglo XX (Ga ya n y Dattwyler, 2017), ha sta las manifestaciones de «Chiloé esta priva o» en 2016 (Mondaca, 2017), las disputas por los bienes comunes del mar se han organiza do en tomo de la legitimidad de los regímenes de a propiación y de los potenciales usuarios de los recursos naturales.

La resolución de las disputas ha pasado, generalmente, por la construcción de arreglos institucionalesque han organiza do el acceso y uso de los bienescomunes sobre la base de sistemas legalesy/o normasconsuetud ina rias. Muchos de losc ualeshan operado de manera simultánea y sobrepuesta (Gelcich et al. 2006).

En el caso delacceso y uso de losbienescomunesdel marporparte de lospueblosindígenas, el reconocimiento de derechos ha sido reciente y se enmarca en reivindicaciones de mayoralcance asociadasa losconflic tos de tenencia de tiemasy los impactos ambienta les de industria sextra c tivas y energétic a sen sustemitorios. En efecto, se rec lama la explotación desmesura da de los recursos naturales con fines ec onómic os (Bebbington, 2009; Gudynas, 2012), a través de la moviliza ción por la recuperación y/ o a seguramiento del uso y manejo de recursosy espacioscomunes (Ospina et al. 2014).

En el año 1991 se promulgó en Chile la Ley General de Pesca y Acuicultura (LGPA), la que desde sus inic ios impactó en la forma de vida de las comunidades Mapuche al no reconocer los usos indígenas de la zona marino-costera, ni sus formas de organiza ción. Los efectos 
de la ley de pesca, junto con otros hechos significativos, impulsaron -en la década de los noventa- la movilización indígena que motivó la crea ción de la Ley 20.249 o Ley Lafkenche, casi 20 años después de promulga da la LGPA. Este proceso de movilización de largo a liento, implicó un trabajo de socialización local del funcionamiento de la ley de pesca, así como de los impactos económicos y ambientales que provocańa en el mediano y largo plazo. Las comunidades indígenas se artic ula ron con el objetivo de identific a r conflictos y amenazas comunes, e intercambiar ideas que les permitiesen construir una estrategia de defensa de la vida en el mar. Al mismo tiempo, el diálogo pemanente entre los teritorios indígenas propició la recuperación de saberes relacionados al espacio marino, los que se emplearon para construir la narrativa que sustentó la propuesta de ley que dirigieron al poder ejecutivo (Huenul, 2012). De esta forma, se reconoce que el origen comunitario y local de la Ley Lafkenche es un hecho inédito en Chile, pues fue impulsado desde abajo hacia a riba poractoreslocales, la población indígena y representantes de la sociedad civil (Nahuelpan, 2016; Espinoza, 2016). A este proceso partic ipativo y local se unieron equipos téc nic os y polític os del Programa Servic io País y del gobiemo, con quienes se trabajó en las negocia ciones con los diferentes organismos del Estado para la elaboración del proyec to de Ley Lafkenc he que crea los Espacios Costeros Marinos para Pueblos O riginarios, conocidoscomo ECMPOs.

La Ley Lafkenche, promulgada el año 2008, procura resguardar los usos consuetudinarios practic a dos por la scomunida desindígenasen área sespec ífic a de la zona ma rino costera, pormedio de la creación de losECMPOS. En su artíc ulo $3^{\circ}$ la Ley indica: «C réa se el espa cio costero marino de pueblosoriginarios, cuyo objetivo será resguardarel uso consuetudina rio de dichosespacios, a fin de mantener lastradicionesy el uso de los recursos naturales por parte de las comunidades vinculadas al borde costero».

Administrativamente, la Ley Lafkenche se sitúa en un aparato político cuyos programas están sujetos a una perspectiva economicista y una trayectoria marcada por la intervención desa rollista (Vergara et al., 2005). A su vez este escenario cuenta con disposiciones lega les de carácter intemacional que noman la relación entre el Esta do chileno y los pueblos originarios, tales como el Convenio 169 de la Organización Intemacional de Trabajo (OIT) y la Declaración de las Naciones Unidas sobre Derechos de los Pueblos indígenas; donde se reconoce explíc itamente el derecho a mantener y forta lec er la rela ción espiritual con las tierras, temitorios, aguas, mares costeros y otros recursos que tra dic ionalmente han ocupado los pueblos indígenas (Gissi et al., 2017).

En la actualidad a nivel nacional se han registra do 96 solic itudes de ECMPOs que abarcan más de 3,5 millones de hectá reasen el país; de ese total sola mente 12 han sido dec lara das. Teritoria Imente hablando, las solic itudes se concentran en la zona sur de Chile, concretamente entre la región del Bío Bío y la región de Aysén. La región de Los Lagos alberga la mayońa de solic itudespara la creación de ECMPOs, con un total de 70 entre el año 2009 al presente, estas se extienden desde la comuna de San J uan de la Costa por el norte hasta la comuna de Quellón por el sur (Araos et al., 2020). Con su creación, las comunida des han 
logrado disputar la posesión del temitorio costero y hacerfrente al deterioro de los recursos comunes. Estos espacios, junto con las concesiones de a cuic ultura y las áreas ma rinas protegidas, son lossistemas de mayor relevancia para la asigna ción de tenencia marina (Tecklin, 2015). No obstante, aun cuando comparten la relevancia con las nombradas estrategias de asignac ión de recursos, losECMPOsse han constituid o como herramientas de resistencia a la tramitación de otros sistemas de asigna ción sobre el mismo espacio. En la figura 1, se a precia las dimensiones de las solic itudes de ECMPOs en los casos de estudio, particularmente en las comunas de Calbuco, Puerto Montt y Cochamó:

Figura 1:

Mapa de la distribución y estado de los ECMPOs en la provincia de Lanquihue.

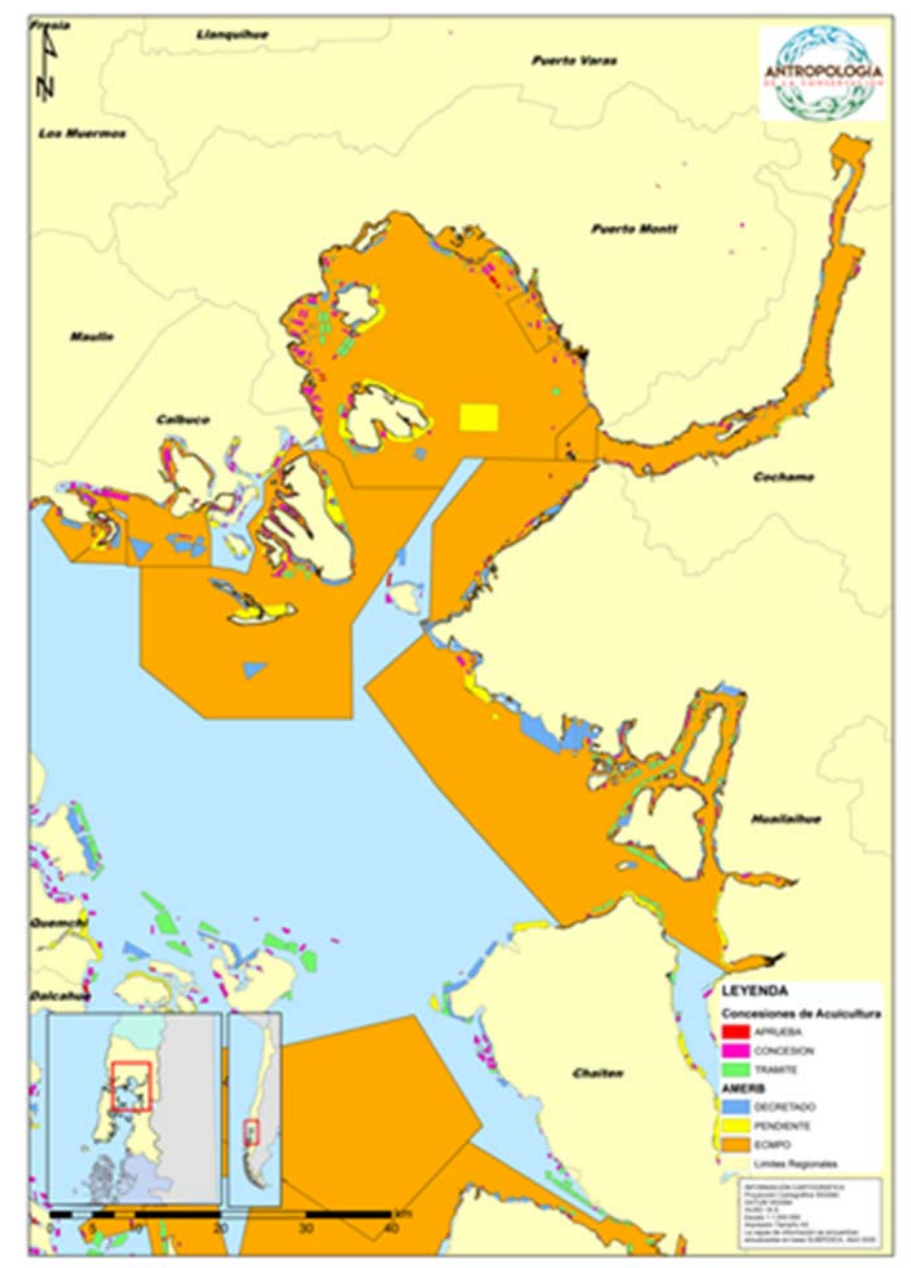

Fuente: elaborado por Francisco Brañas, datos SUBPESCA.

Aplic ando la propuesta a na lítica de la Ecología Política Neo-institucionalista (Haller, 2019), el presente trabajo busca comprender el proceso de construcción institucional para el manejo de recursos comunes. Para ello se a naliza la construcción de discursos empleados 
para legitimar la posición de los diferentes grupos de interés, respecto de la creación e implementación de los ECMPOs. El artículo comprende un aparta do teónico que abarca la reflexión sobre los recursos comunes, junto con las directrices teóricas del enfoque de la Ecología Política Neo-institucionalista y la perspectiva de encuadre utilizada para revisar los discursos de los actores. Luego de una serie de apreciaciones metodológicas, se da paso a los resultados donde se explora las condiciones políticas, económic as y ecológicas de la recuperación de los comunes. Además, se ilustra la construcción de discursos como fuente de legitimida d para la posición de los sta keholders. Fina Imente, se disc ute la relevancia de la construc ción instituc ional en un contexto donde múltiples usos deben concilia rse.

\section{Una propuesta para el estudio de la construc ción institucional de los rec ursos comunes}

Los bienes comunes, son recursos compartidos, independientes de cualquier sistema de derechos de propiedad (Bollier, 2008), cuyo uso sustentable requiere de la cooperación entre las partes. De acuerdo con Ostrom (1990), los recursos de uso común son un sistema de recursos na tura leso construid os porpersonas, cuyas grandes dimensiones vuelven costosa la exclusión de potencia les destinata rios de los benefic ios de su uso. Dic ho sistema comparte doscaracteństic as centra les: la sustrac tabilidad, esdecir, el uso porparte de un usuano afecta la disponibilidad total del recurso; y la exclusión, referida a que la exclusión de potenciales usuarios es imposible o altamente costosa (Ostrom, 1990). Por ello, la manera en que se resuelven los criterios de equidad en elacceso y la partic ipación de losusua riosen eluso de losrecursoscomunesesesencial para la mantención de la sustenta bilidad ecológica y soc ial de los sistemas (Helfrich y Haas, 2008).

Como propuesta política, los comunes nos sitúan sobre el uso de recursos y bienes que conforman nuestro patrimonio social, natural y cultural (Helfrich, 2008), y nos ayudan a entender losprocesos de erosión, conc entrac ión y confina miento de rec ursosna tura les, sociales y cultura les; como los peces, el agua, las zonas de pastoreo y los bosques. Éstos son una a mplia clase de recursos sobre loscua lesla ciudada nía y gruposespecífic os de la sociedad tienen intereses económic os, polític os y morales a socia dos a su control y manejo, sobre la base de relaciones, valores e identidades sociales (Bollier, 2008). Así mismo, el proceso de defensa de los bienes comunes puede contribuir al surgimiento de fomas sociales de cooperación y solidaridad (Castro, 2008). Estos bienes pueden ser pensa dos como sistemas compuestospor elementos rela ciona dos (usuariosy recurso sna turales), c uyos límites se construyen a partir de su funcionamiento como sistema integrado y de los mejores arreglos instituc ionalespara su manejo de manera sostenible. En este sentido, un sistema esun acervo de recursos (E.j. océanos o zona de pastoreo) que un grupo humano puede usar sin comprometer la productividad. A su vez el sistema genera/produce unidades de recursos (flujos) que son a quellas partes del sistema posibles de ser a propiadas, como por ejemplo, estoques de pecesy pastiza les (Ostrom, 1990).

Los sistemas están sujetos a a rreg los instituc iona les que regulan el acceso y uso a los recursos. En ellos, los ind ividuos y grupos pueden utilizar restric ciones diferentes de las impuestas 
por el derecho de propiedad (Benkler, 2008). Dichas instituciones pueden comprenderse como reglas que estructuran las acciones de las personas en contextos particulares y que deben tener en cuenta lascondiciones de exclusión y sustrac tabilidad menciona dasantenomente. Las reg las existentes en cada contexto, determinan la sforma s en que los actores usan y gobieman los recursos de uso. Además, la necesidad de establecer reglas cla ras y eficacespara daracceso y uso a un recurso compartido influye en los diferentes gradosde éxito de las instituciones (Ostrom, 1990).

Dada la complejidad de los recursos a niveles locales, regionales y nacionales se requieren de sistemas complejos de gobemanza que involuc ren diferentes ac tores en distintos niveles de las escalas geográficas y administrativas (Ostrom, 2009). La mantención de relaciones sociales tejida s entre la comunidad y su entomo natural y cultural están sujeta sa la acción colectiva para hacer frente a los problemas que enfrentan en la utilización de recursos de uso común. Así mismo, la capacidad de auto-organización voluntaria del grupo de usuanos para perseguir benefic ios grupa les depende de un sistema de autogestión y derechos de consenso para controlar el acceso y el uso de un recurso, así como también para resolver los problemas de provisión y apropiación, reconocidos como dilemas de la acción colectiva (Ostrom, 1990). Si bien es cierto el marco de análisis institucional y desarrollo de Elinor Ostrom toma en cuenta las condiciones de contexto, los escenarios de acción y las interacciones entre actores en el diseño institucional para la gestión de bienes comunes (Merino, 2014), se hace manifiesta la necesidad de articularlo con la cuestión del poder (Fabinyi, Evansy Foale, 2014).

Con el objetivo de vincular el cambio institucional con las relaciones de poder y la ideología en el estudio de los comunes, se emplearán los planteamientos de la New Political Institutional Ecology (NIPE) propuesta por el antropólogo Tobias Haller (2019).

\section{E enfoque de la Ecología Política Neo-institucionalista}

El enfoque de la Ecología Política Neo-instituciona lista ${ }^{1}$, es el resulta do de la combinación teórica del horizonte de la ecología política junto con el nuevo institucionalismo proveniente de la antropología social y otras disciplinas sociales (North, 1990; Ensminger, 1992; Haller, 2013). Esta combina c ión c nític a esútil para la comprensión de los poderese intereses de los diferentes actores en la gobemanza de los recursos de uso común. NIPE pemite develarla forma en que la interrela ción histórica de dinámic a sextema se intemas, así como las dirigidas por el mercado, conduc en a estra tegias de selección y justific ac ión de instituciones (selec ción de nomasy regla mentos) porparte de los diferentesactores involuc ra dos en el uso y explota ción de los recursos comunes (Ha ller, 2019).

Concretamente, el enfoque de la ecología política dinge la atención hacia narrativas y discursos dominantes que son utilizados estratégicamente por los actores para construir

\footnotetext{
${ }^{1}$ Traducción propia de New Institutional Political Ecology (Haller, 2019).
} 
visioneso marcos de referencia acerca del uso de losrecursos. En este actuarestra tégic o, se materia liza el proceso político de negociación del poder. Así se agrega al a nálisis las formas que adoptan -y las consecuencias que tienen- las a simetrías de poder en las comunidadeslocales donde se esconden procesos de dependencia conducida histórica, política e ideológic amente referidas-cada vez más- a escalas globales y locales.

Siguiendo el trabajo de la antropóloga Jean Ensminger, el nuevo institucionalismo explica los factores interrelacionados que conducen al cambio institucional, donde los derechos de propiedad son transforma dosy elegidos en el transc urso del tiempo. Para ello se enfoca en tres tipos de fa c to res extemos: a mbienta les(lega les, polític os, ec onómic osy ec ológic os), demográficos (aumento de población interesada en un área de recursos de uso común) y tec nológicos (avances en materias de comunicación, conectividad, tecnologías de extracción o faena). Por su parte, la construcción y selección institucional se realiza en el contexto local, cuyosefectos impactan en la disponibilidad, uso y distribución de los recursos comunes (ver figura 2). La selec ción instituc ional, por la tanto, oc urre en un contexto de múltiples a ltemativas que se distingue por la visión fragmentada que tiene el Estado sobre losrecursos, y que queda de ma nifiesto en una diversidad de instituc iones a cargo de cada fragmento. Esta fragmentación minimiza las instituc iones locales pre-existentes y deriva en una desconexión institucional-temitorial de las mismas, priorizando la transformación de los recursos en comodities (Ha ller, 2019).

Figura 2:

Modelo de Cambio Institucional.

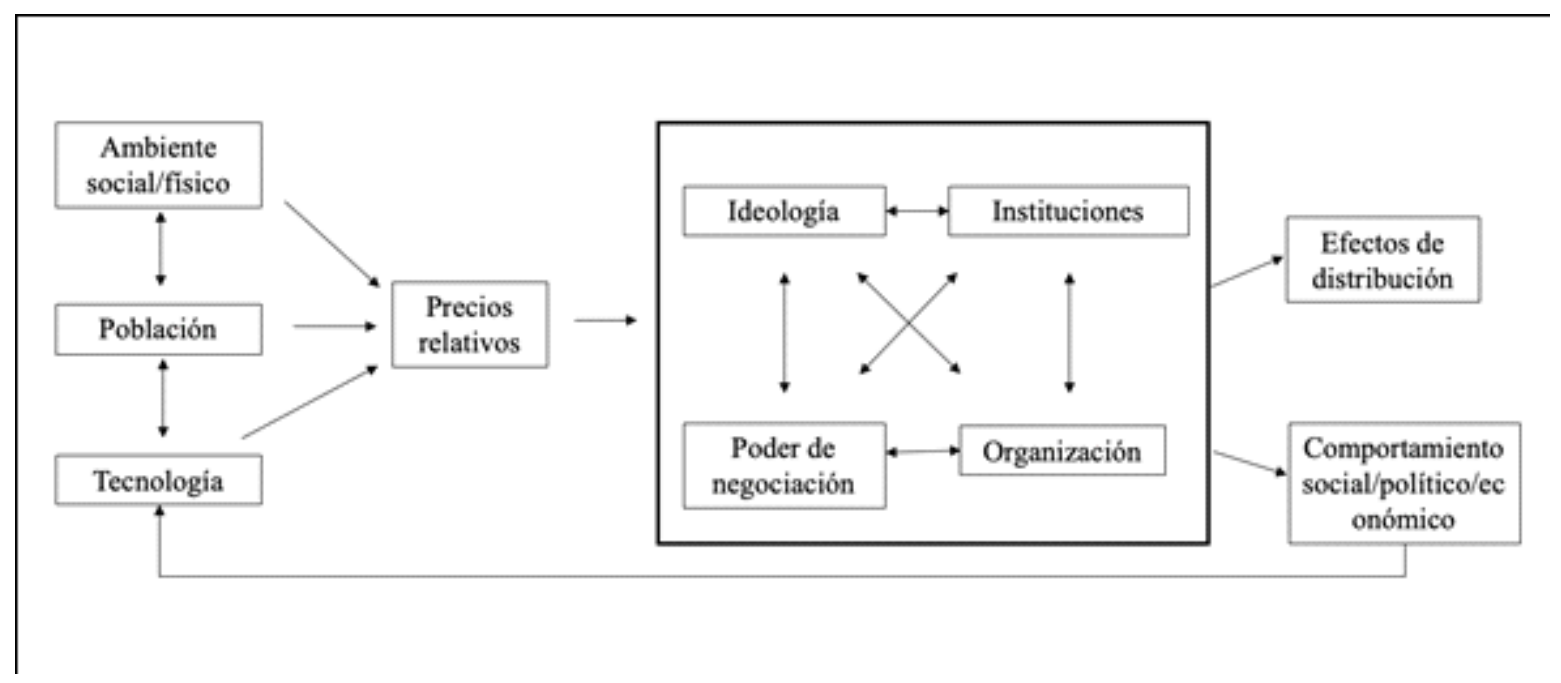

Fuente: Ensminger, 1992.

A partir del trabajo con instituc iones de manejo y control de los rec ursos comunesen países sub-desarrollados, particulamente en África, Haller introduce en el esquema del cambio instituc ional de Ensminger la dimensión del poder (Haller 2013, 2019). Así, reconoce que los factores extemos de cambio institucional forman parte de paisajes culturales que han sido 
segmenta dosc on la creación de esferaslegales, regla mentosy orga niza cionesque benefic ian a actores poderososy elites neo libera les para la inversión y privatiza ción de recursos en el contexto de acumulación por desposesión (Harvey, 2007). Las instituciones estata les responsables del manejo de todos los fragmentos de los recursos están sujetas a una situación paradojal pues se encuentran presentes a través de leyesy reglas específic as que otorgan acceso a los recursos, pero al mismo tiempo se encuentran ausentes dada su incapacidad humana, de infraestructura y financiera para a dministra rlos, posibilitando un régimen de propiedad conocido como acceso abierto de facto (Haller, 2010). De esta forma, el poder de decisión sobre los recursosse concentra en inversorespriva dosy grandesconsorciosaumenta ndo la dific ultad de acceso y uso a comunidades locales, socavando estrategias de subsistencia.

De esta manera, a partir del foco en las relaciones y estructuras de poder en la regulación de los recursos comunes - tomado desde la ecología política -, Haller propone una adaptación del modelo de Ensminger que resulta fructífera para comprender el impacto de las a simetrías de poder entre a c tores comprometidos en la construcc cón y selecc ión de instituciones para el manejo de recursos comunes. Haller incorpora el a nálisis del poder en ca da uno de los componentes básicos del modelo de Ensminger: en los factores extemos (contexto de las relaciones de poder, predisposic iones y poder de decisión); en los precios (cadena de valor); en las variables loc ales (instituciones, organizaciones, negociación e ideología); y en los efectos o resulta dos (distribución y acción colec tiva) (ver figura 3).

Este modelo toma posible comprenderla degradación y cuidado de los recursos comunes a partir de este entramado de factores y variables: globales y locales, estructurales y de acción colec tiva, materialesy subjetivas, cuyo resulta do esuna comprensión máscabal de las trayectorias de desarrollo de un detemina do sistema de recursos natura les.

Figura 3:

\section{Modelo de Análisis NIPE.}

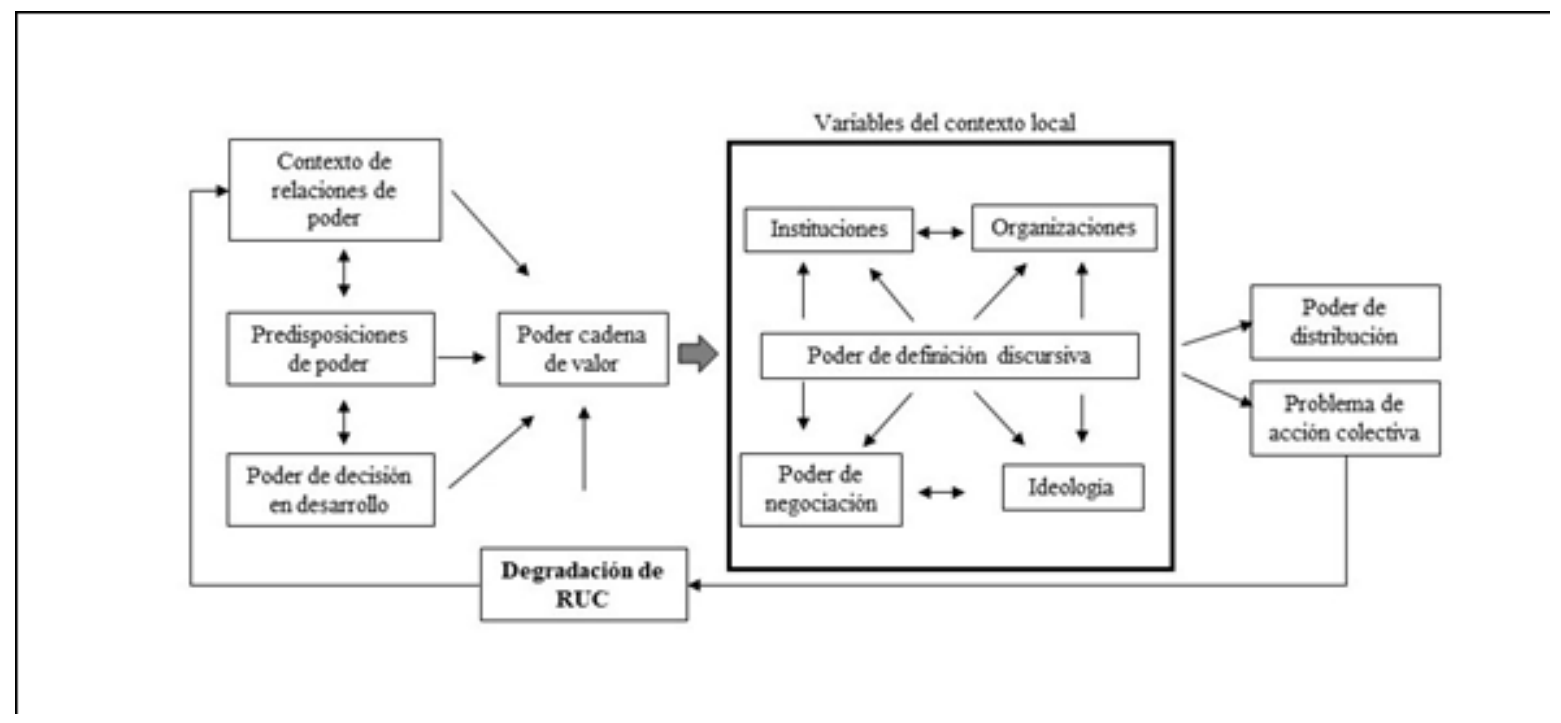

Fuente: Haller, 2019. 


\section{Frame: narrativas y discursos en el proceso de construcción institucional}

Las disputa spor los recursos de uso común se expresan en disc ursos y na rra tiva semplea dos por los ac tores en el proceso de construc ción institucional. Estos son varia dos según el lugar que ocupan los hablantes y se utilizan para construir visiones sobre los EC MPOsy el impacto que estos tendrían en el temitorio, la economía, cultura y sociedad. Las estrategias de los grupos para (re)producir las condiciones de poder en el nuevo contexto de disputa, se expresan estratégic a mente a través de la prensa, comunic a dosy entrevistas. Bajo este marco, la perspectiva teórica del enmarcado o framing pemite indagar en los discursos y na rativas que sustentan la selec ción instituc ional de los a c tores, revelando la acción estra tégica de seleccionar determinadas dimensiones de una realidad percibida para promover una definición, interpretación, evaluación o recomendación del tema (Entman, 1993).

La metáfora del marco (frame) utiliza da porprimera vezen «Stepsto an Ec ology of Mind »de Bateson (1972), representó el proc eso so c ioc ognitivo de determina rlos límites de un conjunto de mensajeso de una clase de acciones signific a tivas. Este tipo de a nálisis fue retoma do por Goffman (2001), para descubrir los principios organizativos que regulan y vinculan los encuentros cotidia nos (Lindstedt, 2018). Su objetivo es rec onoc er que lascirc unsta ncias las convencionessociales ejercen una fuerte influencia en laspersonasy que la vida social de los sujetos contiene marcos o formas de organizar la experiencia que se manifiestan en la interacción. Para este estudio, la importancia de la interacción está dada por ser el espacio de negociación de disc ursosy na rra tiva sque encausa n el manejo de recursoscomunes. Los marcos de la experiencia, entendidos como anda miajes estructura les que orientan la interacción (Galindo, 2015), permiten diferenciar lo que está a dentro y afuera de una situac ión detemina da, otorga ndo vínc ulos entre los intereses, valoresy creencias individuales, y objetos e ideologías de la organización (Snow, 2008).

El encuadre, entonces, será estudiado como un proceso rec ursivo (Lindstedt, 2018) que permite conc eptua lizary representar cómo los a ctoresloc ales disputan y generan estra tég icamente marcospara estructurar el conflicto. Cada vez se reconoce más que los problemas socio ambientales son multidimensionales, políticos, están cargados de valores, son moldea dos por el contexto y la esca la, y están sujetos a múltiples enc ua dres (Lele et al., 2018). La investigación abarca los contextos de experiencia de los actores que se delimitan teniendo en cuenta la selecc iones ra ciona les, pero ta mbién losc onflic tos de lea lta d, a preciaciones estéticas, dudas éticas o preferencias políticas (Cefaï, 2011) de los sujetos que intera ctúan. Portanto, a tra vés de este ejerc icio, se a spira comprenderla percepción de los actores loca les sobre la situa ción problemática a la están confronta dos y los disc ursos que utiliza n para comprometerse en, y muc ha s vec es defender, la construcc cón instituc ional. En estas a c ciones colectivas es donde se pone en juego la práctica de evaluar y encontrar la co-responsabilidad de los sujetos en tomo a los ideales del bien común. Las acciones a sociativa sa escala local remodelan loscampos de experiencia y los horizontes de expectativas, priva dosy públicosde losactores, donde el medio ambiente se transforma en cosa pública (Latour y Weibel, 2005). Estas acciones identifican problemas que son comunes, 
favoreciendo la producción de estrategias de gobemanza y posibilitando la persecución de proyectos colectivos.

\section{Aproximación Metodológica}

La presente aproximación al enfoque de la Ecología Política Neo-institucionalista se sitúa en la a plic ación de la Ley 20.249 o Ley Lafkenche que entrega la administración de la zona marino-costera a comunidades o asociaciones de comunidades indígenas chilenas. Este a ná lisis rec onstruye el contexto na cional de esta norma tiva y su a plic a ción en la región de Los Lagos, ubic a da en el sura ustral de Chile, que se ca racteriza por un habita ren consta nte tránsito entre el mary la tierra. Además, en esta región se concentran la mayoría de las solic itudes de ECMPOscon un marca do interés por defenderlos recursoscomunes de las formas productivas perjudiciales para la zona marino-costera y el habitar de las comunidades.

En este contexto, la investiga ción indaga en la construc ción institucional para el ma nejo de recursos comunes a través de tres casos seleccionados por compartir un Área G eoc ultura I C ostera Ma rítima (AGCM) (Álvarezet al., 2019), espa cio que compa rte ca racterístic as socia les y cultura les y desafía las fronteras a dministra tivas gubemamentales. Tal como se observa en la tabla 1, el presente artículo se sustenta en la revisión de documentos de diferentestiposque abarcan temporalmente desde el año 2010 al año 2020, y que proporcionan información sobre los discursos y narrativas emplea dos por los actores en la disputa por recursos de uso común.

Tábla 1:

Categońas de documentos analizados.

\begin{tabular}{|c|c|c|}
\hline Categorías & Subcategorías & Cantidad \\
\hline Documentos & & 4 \\
\hline \multicolumn{3}{|l|}{ Gubernamentales } \\
\hline Comunicados de & & 9 \\
\hline \multicolumn{3}{|l|}{ Comunidades Indígenas } \\
\hline \multirow[t]{4}{*}{ Documentos de prensa } & Prensa acuícola & 10 \\
\hline & Prensa de economía e inversión & 7 \\
\hline & Prensa gremial & 2 \\
\hline & Prensa independiente & 16 \\
\hline \multirow[t]{2}{*}{ Entrevistas en profundidad } & & 9 \\
\hline & Total & 57 \\
\hline
\end{tabular}

Fuente: Elaboración propia. 
A partir del uso del encuadre o framing se abordan las referencias espacio-temporales y argumentoscon que los actoresordenan los sucesos rela ciona dosa la aplic ación de la Ley Lafkenche. La recopilación intensiva de las notas de prensa, comunic a dos y entrevistas se trabajó mediante las premisas del a ná lisis crítico de disc urso cuyo foco ra dica en la reproducc ión del poder social, identificando los recursos utiliza dos por los a c tores para mantener y legitimar el poder y posición social (Van Dijk, 2009). La premisa del a nálisis crítico se basa en el estudio del disc urso como práctica social (Fairclough, 2008) que delata los vínculos difusos entre discurso, ideología y poder (Baker, 2010). Estas opacidades del discurso encausan la selec ción institucional en las disputas por el ma nejo de los rec ursos comunes. El a ná lisis se llevó a cabo mediante el programa Atlas.ti, hemamienta cualitativa que permitió segmentar los datos, codific a rlos y establecer una visión relacional entre categońas que emergen del enfoque NIPE. El proceso de a ná lisis contempló la seta pas de i) a ná lisis de informa ción de prensa, comunica dos de actores e informa ción gubemamental ii) a nálisis de entrevista s rea liza das en terreno y suministra das por el proyec to FONDECYTno 11180066 . De este proceso emergieron los a ndamiajes estruc tura les que orientan la interacción de los actores y con los que tratan la complejidad de la disputa por los recursos comunes.

\section{Resultados}

\section{Hacia la recuperación de los comunes en la Provincia de Lanquihue}

Los tres casos de estudio se ubic an el norte del Seno del Relonca ví, golfo que constituye la entrada portuaria al sur austral del país y que está marcada por un gran interés por parte de la salmonicultura y producción de mitílidos. En el caso de Puerto Montt, capital regional y polo urbano donde se concentran servic ios públicose institucionesque a dministran los recursos comunes, se manifiesta la tensión permanente entre las diferentes formas de habitar la zona marino-costera y la producción extractiva de la industria sa Imonera. Al este de la capital regional, en el Estua rio del Relonca ví, se ubica la comuna de Cochamó. Esta entrada de marde aproxima damente $55 \mathrm{kms}$ de largo y 4 kms en su parte más ancha, es reconocida por sus característic as hidrobiológicas favorables a la producc ción de mitílidos y el c ultivo de espec ies sa Imoníd eas. El estua rio es un sistema cerrado de recursos donde la presencia de los múltiplesusuarios escontigua, sobrepuesta y requiere de coordinación para el trabajo en la zona. El tercercaso esla comuna de Calbuco, que se ubic a al oeste de la capital regional y entrega su nombre a un archipiélago compuesto por 16 islas en medio del golfo de Ancud. En la actualidad está zona es de gran interés por su puerto industrial que moviliza, entre otras cosas, parte importante de los hidrocarburos que se distribuyen en la zona austral del país.

\section{Regímenes de propiedad, fac tores extemos y cambio institucional}

En la base del conflicto por los comunes del mar en esta zona de Chile, se identific a la transformación de las políticas del Estado chileno en torno a la explotación de recursos 
naturales. Ejemplo de estas reformas fue la conversión productiva de las regiones del pa ís para incentivar el desarrollo tec nológic o y a celera r los procesos productivos basadosen recursos na tura les(Bustos, 2012). La implanta ción de la economía neoliberal consolidó la apertura al comercio exterior con incentivos y facilidades para la inversión extra njera, constituyendo a los empresarios como a ctores polític os artic ula dos bajo la idea modemización e innovación del país (Álva rez, 2015). Desde ese entonces, la ideología neolibera I ha impulsa do un discurso triunfa lista -sobre todo en lo referente al crecimiento económico (Sunkel, 1998)-, que hoy es aplicado por la industria acuícola en la disputa por el manejo de los comunes.

En este marco, en la región de Los Lagos, se generaron incentivosal sector privado para desarrollar la industria a cuíc ola que motivó la a propiación del maritorio ${ }^{2}$ en tanto este correspondía a un espacio marginal y aislado (Núñez et al., 2017) disponible para su explota ción ec onómica. Con ello, los bienes comunes fueron sometid os a regímenes de concesión (Fuentes, 2013) y emplea dospara la extra c ción y consumo direc to de recursos natura les o bien su utiliza ción como so porte para a ctivida des económicas. Para ilustrar este proceso, en el caso de Cochamó -hasta antes de la imupción de la salmonic ulturala extrac c ión de recursos se destinaba principa Imente al consumo fa milia ra tra vés de la recolección de orilla y el trabajo en base a las mareas. Sin embargo, en la década de los 80 durante la instala ción salmonera, se consolidó la explota ción mediante concesiones que posibilitaron la exclusión de otros stakeholders, -principalmente pescadores artesanales y buzos-. Bajo esta lógica de privatización, se dirigió la actividad productiva mediante áreas de uso exclusivo:

«La mayoría de los que hacían pesca años anteriorescasi todos se pasaron a hacer trabajos en mitílidos. Lo que más se ve aquí es mitílidos y centro de cultivo de salmones. [...] hay únic os dueños como también hay sindic atos de pescadores.» (Entrevista Capitanía de Puerto, Cochamó).

Actualmente, la privatiza c ión del estua rio media nte concesiones se traduce en la necesidad de establecer acuerdos para armonizar los múltiples usos de los comunes. Además, la pre-existencia de lasconcesiones (de sa Imonerosy mitilic ultores) es un a rgumento para la negociación entre actores:

«Nosotros obtuvimos antes que ellos entraran a la ECMPO. Nosotros ya eramos titulares de las concesiones y por lo tanto eso queda a parte de lo que ellos solicitaron. Pero también esta organiza ción nos ha estado dando permisos tra nsitorios, nos da el certific ado que ellos no se oponen para que use la gente. En algunos casos.» (Entrevista Mitilic ultor, Cochamó).

Las comunidades indígenas, c on el objetivo de mantener sus modos de vida, se organizaron para aplicarla Ley Lafkenc he como principal herramienta institucional que favo-

\footnotetext{
2 En el presente escrito maritorio se comprende como un concepto que representa las dinámicas teritoriales en donde la presencia marítima se confunde con la terrestre de manera intersticial (Álva rez et al, 2019). Siguiendo a los autores, el maritorio da cuenta de la transicionalidad de habitar mar-tierra, o viceversa.
} 
rece la protección de la zona costera en el sur austral del país (Ara os et al. 2020). Ésta es fruto de la resistencia local a la lógica de privatización de los comunes y reclama el derecho a su recuperación democrática para a ejercer múltiples usos asocia dos a la identidad cultural, «primero fue la tierra, hoy es el mar» (Identidad Territorial Lafkenche, 2017). Desde aquí, la disputa por los comunes moviliza a empresarios, pequeños productores, al Estado y a las comunidades para crear una agenda de defensa de sus intereses. El antagonismo entre comunida des indígenas, Esta do y empresas ha sido parte del contexto so cio-cultural donde se expresan las visiones contra stantes de los actores sobre los bienes comunes (De la Cuadra, 2013).

Las comunidades artic ula das bajo la idea de que los comunes están siendo a menazados, construyen la narrativa sobre el dañino modelo de desarrollo impulsa do por el Estado que favorece a inversionistas y perjudica a quienes continuarán habitando la zona aun cuando hayan heredado de la industria «un desierto, un mar muerto y/o terrenos que no siven para nada» (Ñancuc heo, 2016).

Las predisposic iones de poder (ver Figura 2) que subyacen a las relac iones entre los distintos stakeholders se vinculan a transforma ciones demográfic as que derivan del desarollo de la industria acuícola. Como fue la llegada de personal para ser parte de los procesos industriales que propició el crecimiento de las ciudades, como en el caso de Calbuco y Puerto Montt, donde se construyeron proyectos residencia lespa ra trabaja dores de la industria portuaria y salmonera. Así, los casos de estudio en la provincia de Llanquihue, se vuelven a tractivos para población en busca de oportunidadeslaborales dado el aumento de puestos de trabajos asociados a la industria (prestación de servicios de alimenta ción, limpieza y comercio). Si bien esta tendencia contribuyó a la incorporación de las comunidades a la fuerza laboral, igualmente se tradujo en discrepancias al interior de ellas a sociadasal impacto ambiental que conlleva la explotación de recursos. Por otro lado, la presencia de salmoneros en los lugares se tra dujo en un a porte para la cotidianeidad de los habitantes del sector, como por ejemplo en el caso de una comunidad en la comuna de Puerto Montt, donde ma nifiestan que los sa Imoneros «eran la a mbulancia del sector, porque losúnic osque tenían vehículo eran ellos, yo, a la hora que se enfermaba a lguien, tenía que partir a donde ellos [...]» (Entrevista integrante Comunidad Indígena, Puerto Montt). Así mismo, el poder que fue adquiriendo la administración productiva de los comunes se tradujo en una mayor presencia de áreas concesionadas y permisos de escasa importancia para el uso particular del mar. 


\section{Figura 4:}

\section{Esquema de análisis NIPE a los recursos comunes marinos del sur austral de Chile}

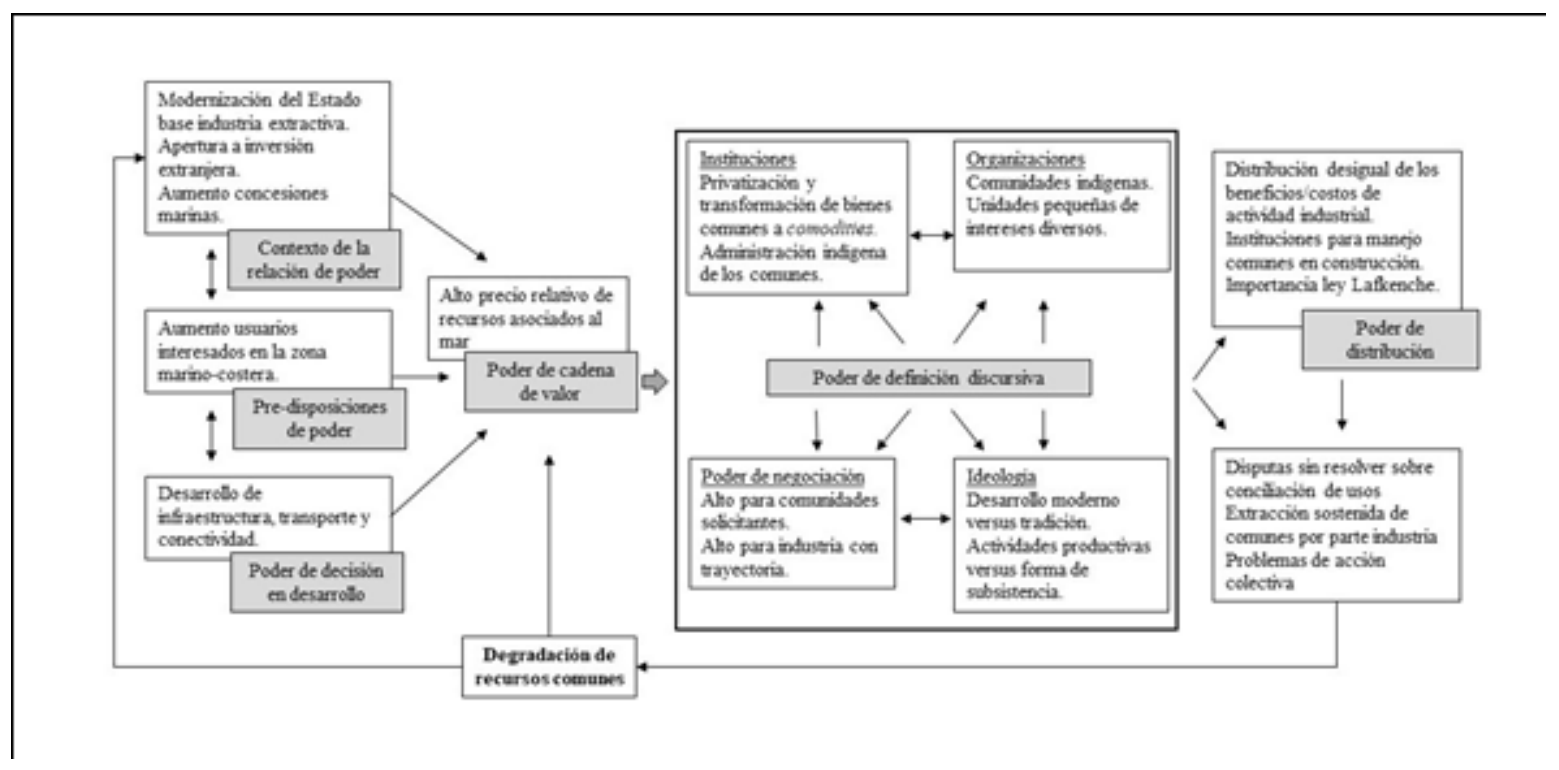

Fuente: elaboración propia en base a la propuesta de Haller (2019).

\section{Definición disc ursiva del poder en el proceso de construcción institucional}

El cambio institucional ocurre sobre la base del pluralismo institucional, en tanto existen variadasopciones con las que los actores pueden disputar el manejo de los comunes. Por una parte, las instituciones estata les encargadas de administrar los bienes naciona les de uso públic o favorecen la privatización de los comunes. Dicha administración se distribuye entre servicios y reglas de gestión dependientes de sectores como fuerzas a madas, servicios de pesca, servicios para pueblosoriginarios y ofic inas municipales. En la práctic a dicha desconcentración representa un obstá culo que se vuelve relevante con la a plicación de la Ley Lafkenche:

$\ll[. .] d e s d$.$e su implementación, ha saca do a la luz otro problema que yo creo que es$ más grave que es la poca organización que tiene el Estado, que es uno solo, pero que delega sus funciones en múltiples instituciones, pero estas múltiples instituciones trabajan cada una por su lado y no existe una coordinación efectiva » (Entrevista Gobiemo Regional de Los Lagos, Puerto Montt).

Por otra parte, la sorga nizac iones gremia les de pesc a d ores a rtesa na lesy mitilic ultores, cuentan con años de experiencia en el desarrollo de actividades productivas orientadas a la obtención de beneficios individuales. Si bien sus trayectorias impulsan la desconfianza hacia solic itudes de ECMPOs de gran enverga dura puesto que restringe sus propiasáreasy su extensión espa cial exc ede la slógic as temitoria les de explota c ión produc tiva; al mismo tiempo se nutren de sus experiencias en negociación para participar de la construcción de acuerdos con las comunidades y visibilizan potenciales benefic ios del trabajo colaborativo: 
$\ll[. .$.$] entoncesind iscrimina da mente había gente que estaba tratando de sobreexplota r$ el recurso, y gracias a la ECMPO se vino a regular el número de concesiones, y también lo que planeamos con la comunidad ahora, es hacer el negocio más sustentable y sostenible en el tiempo. Eso, bueno para nosotros es una buena altemativa el tema de la ECMPO, porque viene a regular una actividad que se ha hecho de manera ind iscriminada por años, permite que las grandes empresas no abarquen todo, y así los pequeños produc tores puedan trabaja r» (Entrevista Mitilic ultor, Coc ha mó).

El sector industrial c uenta con un a lto poderde negociación (ver figura 2) que deriva de su tra yec toria en el desa rrollo económico a nivel nacional y regional. En ello cobra importancia el capital ec onómic o que lespemite rea liza rinversiones y otorga rbenefic iosque repercuten en la calidad de vida de las comunidades. Incluso poseen conexiones polític as a nivel nacional y regional que movilizan en términos de lobby corporativo que logra -entre otrascosas- comprometer la revisión exhaustiva de la noma porparte del gobiemo (Werken rojo, 2017).

El poder industrial se expresa disc ursivamente -en primer lugar- mediante críticas a la Ley 20.249 referida sa su diseño deficiente (Aqua, 2017B) da da la demora en el proceso de tramitación (en promedio 4,5 años) y el efecto suspensivo que tiene la admisión de una solic itud para las concesiones y permisos que se encuentran en proceso. Este congela miento es representado como retraso al desarrollo que afecta a la infraestructura portuaria, proyectos tuństic os, concesiones a cuíc olas o de pequeños mitilic ultores y que daña el crecimiento de la región (El Mercurio, 2017). Así, acusan que la Ley Lafkenche acarrea incertidumbre para las empresas que cuentan con pemisos pero que busc an ampliaciones productivas y mayores inversiones (Cepeda, 2017) o la renovación de permisos de salmonicultores y mitilic ultores(Aqua, 2017A). En segundo lugar, a demás de la pérdida de empleo y desinversión (Aqua, 2017B), el gremio a firma que la llega da de inversionesextra njerasen Chile dependía de la facilidad que el país les entregaba, pero que, desde la promulgación de la Ley Lafkenche, ha sido subyuga do al aumento de la incerteza jurídica en esta materia promoviendo el retiro de ca pita les extra njeros (Musquiz, 2016). En tercer lugar, interpelan al Esta do para que mejore los procedimientos y resuelva de manera oportuna la reclamación de recursos por parte de las comunidades indígenas (Cárdenas, 2018). Entre otras cosas, proponen que se efectúe una real coordinación de los servic ios que participan de las solic itudes(Musquiz, 2018).

Porc ierto, a ojos de representantes de la región en el sena do, la preferencia del uso indígena y las grandes extensiones solic ita das no se ajustan a la realidad, sino que constituyen un abuso ya que «queda claro que no hay otro objetivo que la administración productiva de esta s>(Moreira, 2017).

En este escenario, las comunidades y asociaciones indígenas buscan reivindic ar los usos consuetudinarios materia lese inmateria les de los comunes. Solic itar ECMPOs tiene el objetivo de resguardary proteger los ecosistemas maninos y la cultura (Comunidades Mapuche Lafkenche ECMPO, 2019); para este fin es vital el resguardo de las costumbres mediante derechos colectivos que aun cuando están vigentes en la práctica no son reconocidaspor 
el Esta do (Identidad Temitorial Lafkenche, 2017). Entre otras cosas, ma nifiestan que su interés no es únicamente productivo, sino que se fundamenta en la espinitualidad:

«Las comunidades de los teritorios menciona dos hemos vivido un fuerte proceso colonizador, por esta razon muchos de nosotros recien en este momento de la historia estamos rec onec tand onos con nuestra espintua lidad a nc estral, cuyo funda mento es la reciprocidad entre la comunidad y el itrofill mongen o biodiversidad, y por ende el habitar con respeto para asegurar a las futuras generaciones que puedan seguir disfrutando de ella en nuestros temitorios.»(Coordina dora Willi Lafken Weychan, 2018).

Con la puesta en marcha de la Ley Lafkenche, las comunidadesy a sociaciones indígenas han a umenta do sostenidamente su poder de negociación (ver Figura 2) en ta nto sus decisiones son vinculantes y deteminan la desafección de zonas productivas como concesionesa c uíc olasy permisos ind ividua les. En este proc eso esc la ve el artíc ulo 10 de la Ley 20.249, que obliga la suspensión de cualquier actividad productiva que se emplace en el área del ECMPO desde el momento en que se declare admisible la solic itud.

Entre sus narrativas para la construcción institucional, afiman que la Ley Lafkenche y su figura de administrac ión genera condic ionespara la gobemanza local (AMCAM, 2019), pues «ya es hora de que los actores directamente involuc rados puedan ejercer gobemanza sobre este espac io que utilizan, mirándose a la cara para establecera cuerdos de uso y convivencia.»(Ñancucheo, 2016). A su vez, la ley impulsa el rec onoc imiento del derecho igua litanio de uso de los espacios marinos para quienes estén dispuestos a utilizarlo de manera sustentable y hacen un lla mado ser so c ios estra tég ic os para la a dministra ción conjunta de los comunes (Coordina dora Willi Lafken Weychan, 2017). A razón de lo anterior, para instalar la gobemanza y restringir los efectos de las actividades productivas de extracción de bienes comunes se hace un lla mado al extra ctivismo a cumplir con la nomativa a mbiental vigente (El Ciudadano, 2017). Si bien este instrumento entrega fac ultadeslegales para decidir proyectos que se quieran ejecutar en temitorio marino, reconocen que no otorga el derecho de negarel acceso a todosquienesbusquen pesc ar, bucearo extra era lgas, c ircula r navegar o hacer activida des recreativas siempre que no atenten contra el medio ambiente (ComunidadesMapuc he Lafkenc he ECMPO, 2019).

Los disc ursos a soc ia dos a los EC MPO s como obstá c ulos para la inversión y el desa rro llo son legitima dos por actores provenientes del sector industrial y comercial, quienes fomentan una percepción de incertidumbre y de inestabilidad económica y laboral en el escenario regional y local; presionando con ello a los organismos del Estado para la resolución de los conflictos en favor de sus actividades económicas. Por otra parte, el disc urso legitima do por las comunidades indígenas transita hacia la protección y resguardo del maritorio y la cultura. Lejos de explic ita r una visión homogénea de la scomunida des indígena srespecto a los recursos, las narrativas se tiñen de particularidades temitoriales y tienen el efecto de generar presión hacia el sector industrial y al Estado para el cumplimiento de la legislación vigente asociada a las nomas de calidad ambiental. Ya sea por su carácter noma tivo o por la presión social y mediátic a, las na rativas empleadas por las comunidades indígenas 
tienen por efecto encausar las negociaciones entre grupos de interés hacia prácticas de sustentabilidad ambiental.

\section{Disc usión}

Anteriomente, se revisaron una serie de factoresextemosque generan incentivospara desmantelar los comunesy su a propia ción colectiva, y que se esconden en dependencia económicas y políticas que ha movilizado la administración estatal por décadas. Estos promueven el interés individual o sectorial de los stakeholders por «una parte» de la zona marino-costera y sus recursos natura les, generando las condiciones para la disputa de los comunes y encausando el cambio institucional hacia la privatización.

En la definic ión de los recursos comunes, estosson tratados con independencia de los sistemas de gobemanza con que se administran, para así inc luir ta nto los recursos natura les y como de construc ción humana (Ostrom et al, 1999). Esta distinción entre los comunes y los sistemasde derecho y propiedad revela la existencia de una complejidad institucional y de nomasasociadas a loscomunes. A raíz de lo anterior, no existe un únic o régimen que sea efic iente, justo y sustentable en relación con los recursos y, en efec to, todos tienen efectos diferentes sobre los bienes comunes. En los casos revisados, el cambio institucional y la creación de nomas para el uso sostenible de los recursos depende en gran medida de los contextos instituc iona les existentes (Sick, 2008).

Por una parte, el aumento de la privatización y las tendencias hacia el desarrollismo se tradujo en la transfomación de los comunes en comodities dada la paradojal presencia y a usencia del Esta do en este sistema de explota c ión. La reduc ción del poder del Esta do que deriva de entregar concesiones marinas a grupos inversionistas, a umenta el poder de las élites para a propiarse de los rec ursos mediante su interés económico. Las instituc iones preferentes a la propiedad individual se apoyan en las políticas públic as de conectividad e infraestructura local para inclinar las dinámicas de poder a favor del desarrollo industrial. Las comunidades locales que ven amenaza do el futuro socio-ecológic o de sus teritorios y suspráctic as consuetud ina rias, se comprometen en el desa rollo de estra tegiasinstituciona les que lespermitan satisfacer sus proyec ciones. En este contexto de plura lismo instituc ional, los stakeholders tienen la facultad de construir arreglos institucionales a favor de sus propios intereses; mientras que la industria explota el valor económic o de los comunes, las comunidades abogan por resguardar los ecosistemas y la cultura mediante su administración a través de acuerdos colec tivos.

En el contexto de la provincia de Lanquihue, la justific ación del poder de los sta keholders se nutre de la dicotomía ideológica entre modemidad y tradición (Haller, 2013). Haciendo uso de sus faculta des disc ursivas, el gremio industrial y los pequeños productores destacan nociones como ciudadanía que les pemite referir a la igualdad de derechos de todos los habitantes del país para el uso de los bienes públicos. Para legitimar su poder, el gremio industrial destaca el argumento del desarrollo que los temitorios alcanzan a través de sus 
inversiones. De esta forma, se entrega legitimidad en la construcción instituciones asociadas a la propiedad privada. Si bien, los discursos expresan las relaciones de poder y las estra tegias de a c ción de los sta keholders; el poder de los a c toreses de ca rá c ter tra nsitorio, pues su a umento o disminución está sujeto a los argumentos emplea dos en los espacios de negociación y en el disc urso público.

Al contrario, las comunidades indígenas y locales apelan al valor de los ECMPOs como herramientas de control y administra ción de los comunes, sobre la base de la apropiación colectiva y comunitaria sustentada en a cuerdos a nivel local. En sus na rativa seste manejo posibilita el habitar en concordancia a su manera de entender la relación entre comunidad humana y ecosistema, como parte de un todo interconectado que asegura su sustentabilidad. Así, a bogan por configuraciones de poder enra iza das en sus modos de vida, como habitantes históric os de la zona manino-costera, inc luso desde antes de la conformación del Estado; destacando la pertenencia a culturas ancestrales donde los comunes se manejaban colectivamente mediante acuerdos comunitarios.

En este marco, es importante destacar el rol que cumple la asociatividad en el proceso de construc ción institucional. Así c omo la industria se asocia a téc nic os y consultores encargados de negociar con los otros usuarios interesados, las comunidades se asocian con otras comunidades, organiza ciones indígenas, y ta mbién con a ctores de la sociedad civil, quienesapoyan y via bilizan la solic itud de losECMPOs (Ara oset al. 2020). En losc a sos de estudio, parte importante de la construcción institucional tiene que ver con la formación de acuerdos, estos son funda menta les para definir el camino a seguir y soluc ionar los obstác ulos que emergen en el proceso.

La tendencia a la colaboración para la construcción de acuerdos es influida por la estructura de los grupos sociales, la experiencia individual previa en la acción política y las percepciones de los interesados (Futema et al, 2002). En la actualidad, a la disputa de los comunes subyace el reto de integrar la lógica del mercado y del Estado (Ruiz-Ballesteros y Gual, 2012). En este cometid o, los a cuerd os entre a c tores empresa riales, mitilic ultoresy pescadores con las comunidades indígenas, se han concentra do en la definición espacial de las áreas conc esiona das y la reloca lización de las mismas (Ara os et al. 2020).

Desde otra arista, la disputa por los comunes está sujeta a la distribución desigual de los benefic ios y costos asociados al fenómeno del extractivismo en los casos estudiados (ver Figura 2). Los impuestos de las empresas son pagados en la ca pital nacional en desmedro de las localidades que viven el despojo de sus recursos. En suma, las instituciones para el manejo de los comunesse encuentran en proceso de construc ción. La promulga ción de la Ley Lafkenche posibilita la experiencia inédita de co-construcción institucional, sin embargo, el proceso está determinado tanto por la relación entre actoresque ocupan posiciones a simétric as y las redefinic iones del poder histórico en base a nuevas herramientas como los ECMPOs. A fin de cuentas, la implementación de la Ley 20.249 ha sido un trabajo cuyos a lcances imprevistos -para las comunidades y la industria- son objeto de negociación. 


\section{Conclusiones}

La degradación de los comunes en el sur austral de Chile propiciada por el sistema de concesiones marinas para la acuicultura, se ha sostenido sobre la base de un régimen privatiza dor del espa c io y los recursos manino-costero impulsa do por la industria sa Imonera y el Estado chileno. Este modelo de desarrollo jerarquiza las formas de vida legítimas, y subordina prácticas y conocimientos sobre la base de la dicotomía modemidad/tradición. La recuperación de los comunes es una agenda impulsa da porlas comunidades y fundamentada en el uso consuetudinario del mar y sus recursos. Para la materialización de este proceso, las comunidades desa rrolla n estrategias instituc iona les que comprenden la instalación de mesas de trabajo multisectoriales, donde se busca lograr acuerdos entre los stakeholders que permitan conso lidar los ECMPOs y fundar rela ciones de coopera ción que se manifiesten en los planes de administración y manejo.

El conocimiento que proviene de experiencias de gestión de loscomunes se transforma en sustrato para encausar espacios de negociación hacia la construcción de altemativas instituc iona les que desa fíen las formas polític as y económic as ac tua les.

La Ley Lafkenche es una herramienta -fruto de la acción colectiva- que posibilita la innovación en materia de manejo de los comunes del mara nivel nacional. En la medida que la disp uta involuc ró intereses y nec esida des de los distintos sta keholders, log ró comprometerlos, movilizarlos y potenciar la emergencia de acuerdos y vínculos sociales. En los casos revisados la situación de los comunes se caracteriza por usos múltiples, extractivos y no extractivos, donde los cambios en asignación de derechos de propiedad y sistemas de gestión dificultan la c reación de instituciones y, al mismo tiempo, generan ca mbios dentro de losgrupos de interesadosy entre ellos.

Para los casos revisa dos, el análisis NIPE da cuenta de la interrelación históric a de factores a mbientales, socia les, físic os demográfic os y tec nológ ic os que inciden en el precio rela tivo de los recursos natura les asociados al mar. Visibiliza el fortalecimiento de asimetrías de poder existentes entre los actoresy la gestación de nuevascondiciones de podera tra vés de la consolidación de los ECMPOs. Además, el estudio de la selección institucional y sus vínculos con diferentes ideologías a través de los discursos y narrativas de stakeholders, permite comprender los argumentos que legitiman el comportamiento de los actores sobre los control y uso de los comunes. El a ná lisis de marco pone el acento en la visión de los actores locales sobre el proceso de construcción institucional, la forma en que lo comprenden y conceptua lizan sus demandas. Pud iend o reconocer los disc ursosy na rativa scon que se comprometen en los procesos de negociación y la posibilidad de transformarlos para alcanzar sus intereses en la gestión de los comunes

Fina Imente, a sí como esta investiga c ión visibiliza los disc ursos y na rativas emplea das por los grupos de interés en la disputa de los recursos comunes del mantorio, la proyecciones teóricas y empíric as de esta investiga ción, muestran la viabilidad de a plicar este enfoque 
teórico y metodológico al estudio de otros recursos comunes amenazados por la privatización y el extractivismo industrial, como la tierra, las zonas de pastoreo en la alta montaña, los bosques, la s semillas, entre otros. Por último, rec onoc emos la s limita ntes espaciales y temporales de este estudio, que remiten a un proceso en desarrollo, móvil y en constante transformación.

\section{Agradecimientos}

El artículo es resultado del proyec to ANID/FONDECYT N. 11180066 «CMPOS: Ensamblajes conserva cionistas para la protec ción de lugares de vida en la zona costera de la Región de Los Lagos», a quienesagradecemossu financiamiento y la factibilidad de acceso a la información. Este escrito se desprende del desarrollo de tesis de Florencia Diestre entre 2019 a 2020 para obtenerel gra do de Magísteren Ciencias Socia lescon mención en Soc iología de la Modemización por la Universidad de Chile.

\section{Referencias}

Álva rez, R., (2015). G remios empresariales, polític a y neolibera lismo. Los ca sos de Chile y Penú (1986-2010). Santiago, Chile: LOM Edic iones.

Álva rez, R., Ther-Ríos, F., Skewes, J.C., Hidalgo, C., Carabias, D. y García, C. (2019). Reflexiones sobre el concepto de manitorio y su relevancia para los estudios de Chiloé contemporáneo. Revista Austral de Ciencias Sociales 36, 115126.Doi: doi: 10.4206/rev.austral.cienc.soc.2019.n36-06

AMCAM (23 mayo 2019) Espacio costero marino para comunidades Mapuche Lafkenche Asociación de Municipalidades con Alcalde Mapuche. Recuperado de: https:// www.amcam.cl/post/espacio-costero-ma rino-para-comunid a des-ma puche-la fkenche.

Aqua. (18 julio 2017A) Ley Lafkenche: La noma que complica al borde costero. Aqua Acuicultura + pesca. Recuperado de: https://www.aqua.cl/reportajes/ley-la fkenche-la-norma-complic a-al-borde-c ostero/

(12 septiembre, 2017B) Gremios acuíc olas exigen modificaciones a «ey Lafkenche». Aqua Acuicultura + Pesca. Recupera do de: https:// www.a qua .cl/2017/09/12/g remios-fimas-a cuic ola s-exigen-mo dific a cionesley-la fkenche/

(19 a gosto 2019) Mitilic ultores de Calbuco en alerta por efectos que está provocando solicitud de ECMPO. Aqua. Acuicultura + pesca Recuperado de: https:// www.a qua.cl/2019/08/19/ mitilic ultores-de-ca lbuco-en-a lerta-porefectos-que-esta-provocando-solic itud-de-ec mpo/\#

Araos, F., Catalán, E., Alva rez, R., Núñez, D., Brañas, F. y Riquelme, W. 2020. Espacios Costeros Marinos para Pueblos Orig ina rios usos consuetudina rios y conservación marina. Anuário Antropológico (On line, I).

Anbleyth-Evans, J., Riquelme, W., Hidalgo, C., Brañas, F., Cata lán, E., Núñez, D. y Diestre, F. (2020). Marine Indigenous Areas: Conservation Assemblages for Sustaina bility in So uthem Chile. Coastal Management, 1-19.

Baker, P. (2010). So c iolinguistics and Corpus Linguistics. Ed inburgh, UK: Ed inburgh University Press.

Bateson, G. (1972). Steps to an ecology of mind: Collec ted essa ys in a nthropology, psyc hia try, evolution, and ep istemology. Chic ago, USA: University of Chic ago Press.

Bebbington, A. (2009). Latin America: Contesting extraction, producing geogra phies. Singa pore J oumal of Tro pical Geogra phy, 30(1), 7-12.Doi: https:/ /doi.org/10.1111/j.1467-9493.2008.00349.x 
Benkler, Y. (2008). La economía polític a del procomún. En S. Helfrich (comp.), Genes, bytes y emisiones: Bienes comunes y ciudadanía (pp. 127-136).Ciudad de México, México: Fundación Heinrich Böll.

Bollier, D. (2008). Los bienes comunes: un sector soslayado de la creación de riqueza. En S. Helfrich (comp.), Genes, bytes y emisiones: Bienes comunes y ciudadanía (pp. 30-41). Ciudad de México, Méxic o: Fundación Heinrich Böll.

Bustos, B. (2012). Brote del virus ISA: c risis a mbiental y capacidad de la institucionalidad a mbiental para manejar el conflicto. EURE. Revista latinoamericana de estudios urbano regionales. 38, 219-246. Doi: http://dx.doi.org/ $10.4067 /$ S0250-71612012000300010

Cárdenas, L (22 junio 2018). Informe reserva do de Sofofa critica «pasajes osc uros» de la Ley Lafkenche y será presentado al gobiemo. La Tercera. Rec uperado de: https:// www.latercera.com/la-tercera-pm/notic ia/informe-reservado-deso fofa-c ritic a -pa sajes-osc uros-d e-la-ley-la fkenc he-y-sera-presenta do-al-gobiemo/216494/

Castro, J. E. (2008) Los bienes comunes y la ciuda da nía: contra dic ciones de una relación en pleno desa rrollo. En S. Helfrich (comp.), Genes, bytes y emisiones: Bienes comunes y ciudadanía (pp. 68-80). Ciudad de México, México: Fundación Heinrich Böll.

Cefaï, D. (2011). Diez propuestas para el estudio de las moviliza ciones colectivas. De la experiencia al compromiso. Revista de Sociología (26), 137-166. Doi:10.5354/0719-529X.2011.27491

Cepeda, M. (25 octubre 2017) Ley Lafkenche y el necesario desarrollo costero chileno. Diario Financiero. Recupera do de: https://www.df.cl/noticias/ opinion/c olumnistas/ley-la fkenche-y-el-nec esa rio-d esa rollo-costero-chileno/ 2017-10-24/200930.html? utm so u rce =e mail\&utm medium=email\&utm campaign=Titula res_25102017\&utm content=Link Notā

Comunidades Mapuche Lafkenche ECMPO, Costa de Valdivia, Corral. ( $2 \overline{3}$ julio 2019). Comunidades lafkenche de la costa valdiviana llaman a informarse sobre solicitud de ECMPO. Radio Kurruf. Recuperado de: https:// ra diokumuf.org/2019/07/23/c omunid a des-la fkenc he-de-la-costa-va ld ivia nalla man-a-informa rse-sobre-solic itud-de-ec mpo/

Coordinadora de comunidades Willi Lafken Weychan (14 agosto 2017) Recuperada de: http://www.conapach.cl/wp-content/uploads/2017/09/Declaración-Públic a-Willi-La fken-Weychan-O fic ial.pdf

De la Cuadra, F., (2013). Cambio climatico y conflic to socioambiental. Apuntes sobre el antagonismo entre el pueblo mapuche, el Estado chileno y las empresas En: Postigo (Ed.) Cambio climático, movimientos so ciales y política públicas. Una vinculación necesaria (pp. 217- 238). (1ae ed.). Santiago, Chile: ICAL

El Ciudadano. (13 septiembre 2017) Aplic ación de Ley Lafkenche abre escenario de disputa entre comunidades y empresarios. El Ciudadano. Recuperado de https:// www.elciudadano.cl/orga niza cion-social/a plic acion-d e-leylafkenc he-abre-esc ena rio-de- disputa-entre-comunida des-y-empresa rios/09/ $13 /$

El Merc unio. (12 septiembre 2017) Comunidades piden 3,3 millones de hectareas y empresarios a cusan «inseguridad laboral» El mercurio. Recuperado de: http:// www.ec onomia ynegoc io s.cl/ notic ia s/ notic ias.a sp? id =397088

Ensminger, J . (1992). Ma king a Ma rket. The Institutional Tra nsfo mation of a n Afric a $n$ Soc iety. Cambridge, UK: University Press.

Entman, R. (1993). Framing: Towa rd Cla rification of Fra ctured Pa radigm. Commun 43(4), 51-58.

Espinoza, C. (2016). «Ley del borde costero y cuestión étnic a en chile: del disc urso a la práctica política». Universum, 31(1):123-139.

Fa binyi, M., Eva ns, L, y Foale, S.J . (2014). So c ial-ec ologic al systems, soc ia I diversity, and power: insights from anthropology and political ecology. Ecology and Society 19(4):28. Doi:10.5751/ES-07029-190428

Fa irc lough, N. 2008. El a nálisis crític o del disc urso y la merca ntiliza ción del disc urso público: Las universidades. Disc urso \& Sociedad, 2(1), 170-185.

Fuentes, J. (2013). Análisis compa rado de los regímenes de las concesiones mańtimas y de acuicultura. Revista de Derecho de la Pontificia Universidad Ca- 
tólica de Valparaíso 41, 411-456. Doi: http://dx.doi.org/10.4067/S071868512013000200013

Futema, C., de Castro, F., Silva-Forsberg. M. C. y Ostrom, E. (2002). The Emergence and Outc omes of Collec tive Ac tion: An Institutional a nd Ec osystem Approa ch. Society \& Natural Resources, 15, 503-522 Doi: https://doi.org/10.1080/ 08941920290069146

Galindo, J. (2015). Erving Goffman y el orden de la interacción. Acta Sociológica 66, 11-34. Doi: https://doi.org/10.1016/j.ac so.2014.11.002

Gayan, P. y Dattwyler, R. (2017). «Y serán desplaya dos». Recorido históncico sobre los bienescomunes, pesc a doresa rtesa na lesy control legal del litora I en Chile. Historia Crítica, (63),97-116 ISSN: 0121-1617

Gelc ich, S., Edwards-J ones, G., Kaiser, M. J., y Castilla, J. C. (2006). Comanagement policy can reduce resilience in traditionally managed manine ec osystems. Ec osystems, 9(6), 951-966. Doi: https:// doi.org/10.1007/s10021-0050007-8

Gissi, N., Ibacache, D., Pardo, B., y Ñancucheo, M. (2017). El Esta do chileno, los lafkenche y la Ley 20.249: ¿Indigenismo o política del reconocimiento?. Revista Austral de Ciencias Sociales, 32, 5-21. Doi: https://doi.org/10.4206/ rev.austral.cienc.soc.2017.n32-01

Goffman, E. (2001). La presentación de la persona en la vida cotidiana. Buenos Aires, Argentina:Amo rrortu.

Gudynas, E. (2012). Esta do compensa dor y nuevos extractivismos. Las ambivalencias del progresismo sudamericano. Nueva Sociedad, 237, 128146.

Ha ller, T. (2019). Towa rdsa new institutional political ec ology. How to ma my extemal effects, institutional change and the role of power and ideology in commons studies. En: Haller, T., Breu, T., De Moor, T., Rohr, C., y Znoj, H. (Eds.). The Commons in a Glocal World. Global connections and local responses (pp.90120). Routledge.

(2013). The Contested Floodplain. Institutional Change of the Commons in the Kafue Flats, Zambia. Lanham, MD: Lexington Books.

(2010). Disputing the Floodplains: Institutional Change and the Politics of Resource Management in Afric an Wetlands. Brill: Leiden. Intemational J oumal of the Commons, 7(2), 579. Doi: https://doi.org/10.18352/ijc.451

Harvey, D. (2007). Breve historia del Neoliberalismo. Madrid, España: Akal.

Helfric h, S. (2008). Introduc ción. Bienes comunes y ciudadanía: Una invita ción a compartir. En S. Helfrich (comp.), Genes, bytes y emisiones: Bienes comunes y ciudadanía (pp. 21-26). Ciudad de México, Méxic o: Fundación Heinrich Böll.

Helfrich, S. y Haas, J. (2008). Genes, bytes y emisiones: Acerca del signific ado estra tégic o del debate de los bienes comunes. En S. Helfrich (comp.), Genes, bytes y emisiones: Bienes comunes y ciudadanía (pp. 311-328). Ciudad de México, México: Fundación Heinrich Böll.

Huenul, S. (2012). Construcción sociopolític a de la 'Ley Lafkenche'. En H. Nahuelpan et al. (Ed.), Ta iñ fijke xipa rakizuameluwün, Historia, colonialismo y resistencia desde el país mapuche (pp 209-234). Temuco, Chile: Ediciones Comunidad de Historia Mapuche.

Identidad Teritorial Lafkenche. (14 julio 2017) Comunicado: Identidad Teritorial Lafkenche rebate cuestionamientos a Ley que crea el Espacio Costero Marino de los Pueblos Originarios. Mapuexpress. Recuperado de: https:// www.ma puexp ress.o rg/2017/07/ 14/ c o munic a d o-id entid a d-te rrito ria lla fkenc he-reba te-c uestiona mientos-a-ley-que-c rea-el-espa cio-c ostero-marino-de-los-pueblos-origina rios/

Latour, B. y Weibel, P. (2005). Making Things Public: Atmospheres of Democracy. Karlsnuhe y Cambridge, MA: ZKM, Center for Art and Media y MITPress.

Lele, S., Brondízio, E., Byme, J., Mace, G. y Martinez-Alier, J. (2018). Framing the Environment. En: Rethinking Environmenta lism. Linking J ustice, Susta ina bility and Diversity (pp. 1-22). Cambridge, UK: Strügmann Forum Reports.

Lindstedt, N. (2018). Shifting Frames: Collective Action Framing from a Dialogic and Relational Perspective. Sociology Compass, 12(1). doi:10.1111/soc 4.12548

Merino, L. (2014). Perspectivas sobre la gobemanza de los bienes y la ciudadanía en la obra de Elinor Ostrom. Revista Mexicana de Sociología, 76, 77-104. 
Mondaca, E. (2017). The Archipielago of Chiloé and the uncertain contours of its future: Coloniality, new extractivism and political-social re-vindic ation of existence. En: Environmental Crime in Latin America (pp. 31-55). London, UK: Palgrave Macmillan,

Moreira, I. (15 septiembre 2017) Ley Lafkenche: abuso de poder. Senado. Recuperado de: https:// www.senado.cl/senado/site/a rtic/20170915/pa gs/ 20170915115145.html

Musquiz, L. (16 a bril 2018) «Ley Lafkenche» frena 5\% de las concesiones mańtimas en estado de renovación en el sur. El mercurio, economía y negocios. Recuperado de: http:// www.economia ynegocios.cl/noticias/ notic ia s.asp? id $=460410$

(26 noviembre 2016) Productora de choritos evalúa cerrar su operación en Chile por conflicto con «ey lafquenche». El Mercurio, economía y negocios. Recup era do de: http:// www.ec o nomia ynegocios.cl/ noticia s/ notic ia s. a sp? id $=311998$

Nahuelpan, H. (2016). «Micropolíticas mapuche contra el despojo en el Chile neoliberal. La disputa por el lafkenmapu (temitorio costero) en Mehuín». Izquierdas, 30:89-123

Núñez, A., Aliste Almuna, E., Bello, Á., y Osorio, M. (2017). Imag inarios geog rá fic os, prácticas y discursos de frontera: Aisén-Patagonia desde el texto de la nación. Pontificia Universidad Católica de Chile, Instituto de Geografía.

North, D. (1990). Institutions, Institutional Change and Economic Performance. Cambridge, UK: University Press.

Ñancucheo, M.C (21 mayo 2016) El espacio costero manino de pueblos originanios: una oportunidad para repensar colectivamente la relación con el mar. El desc oncierto. Recupera do de: https:// www.eld esc onc ierto.cl/2016/05/21/ el-espa cio-c ostero-ma rino-de-pueb los-origina rios-una-o portunid a d-pa rarepensa r-colec tiva mente-la-relacion-c on-el-marl

Ospina, P., Bebbington, A., Hollenstein, P., Nussbaum, I., y Ramírez, E. (2014). Extrateritorial Investments, Environmental Crisis, and Collective Action in Latin America. World Development, 73, 32-43. http://dx.doi.org/10.1016/ j.world dev.2014.08.020

Ostrom, E. (1990). Governing the commons: The evolution of institutions for collective action. Cambridge, UK: university press. (2009). Understanding institutional diversity. Princeton university press.

Ostrom, E., Burger, J., Field, C., Norga a rd, R. y Polic ansky, D. (1999). Revisiting the Commons: Local Lessons, G lobal C hallenges. Science, 284(5412), 278-282. doi: 10.1126/sc ience.284.5412.278.

Ruiz-Ballesteros, E. y Gual, M. A. (2012). The Emergence of New Commons: Community and Multi-Level Govemance in the Ecuadorian Coast. Human Ec ology 40, 847-862. Doi: https://doi.org/10.1007/s10745-012-9540-1

Sick, D. (2008). Social Contexts and Consequences of Institutional Change in Common-Pool Resource Management. Society \& Natural Resources 21, 94105. http s:// doi.org/10.1080/08941920701681524

Snow, D. (2008). Elaborating the Disc ursive Contexts of Framing: Disc ursive Fields and Spaces. Studies in Symbolic Interaction, 30: 3-28.

Sunkel, O., (1998). La sostenibilidad del desarrollo vigente en Améric a Latina. En O. Sunkel et al. América Latina en el siglo XXI. De la esperanza a la equidad (pp. 29-82). Ciudad de Méxic o, México: Fondo de Cultura Económica.

Tecklin, D. (2015). La apropiación de la costa chilena: ecología política de los derechos privados en tomo al mayor recurso público del país. En: Prieto, M., B. Bustos y J. Barton. (2015). Ecología Política en Chile: Naturaleza, propiedad, conocimiento y poder (Pp. 121-42). Santiago, Chile: Editorial Universitaria.

Van Dijk, T. A. (2009). Critical discourse studies: A sociocognitive approach. En R. Wodak y M. Meyer (Eds.), Methods of critical discourse a nalysis (pp. 62-87). Londres, UK: Sage.

Vergara, J., Foerster, R. y Gundermann, H. (2005). Instituciones media doras, leg islación y movimiento indígena de DASIN a CONADI (1953-1994). Atenea, 491 (1), 71-85.

Werken rojo. (27 octubre 2017). Chile /Wallmapu - empresaria do sa Imonero en- 
cabeza cruzada anti-ley del borde costero de pueblos originarios Werken rojo. Recupera do de https:// werkenrojo.cl/chile-wallmapu-empresa ria dosa Imonero-enc a beza-c ruza da-a nti-ley-del-borde-costero-d e-pueb los-originarios/

Willi Lafken Weychan (18 julio 2018). Declaración Pública: Coordinadora de Comunidades Mapuche Williche por la Defensa Del Teritorio Willi Lafken Weychan. Observatorio ciudadano. Recupera do de: https://observatorio.cl/ decla ra cion-public a-c oord ina d ora-de-c omunid a des-ma puc he-willic hepor-la-defensa-del-territorio-willi-la fken-weychan/ 